\title{
FREQUENCY OF DYSLIPIDEMIA IN PATIENTS HAVING SUBCLINICAL HYPOTHYROIDISM
}

\author{
Shah Zeb1, Shafaq Naz', Najeeb Ullah² \\ 1. Naseer Teaching Hospital \\ 2. People Primary Healthcare Initiative, Noshehra
}

\begin{abstract}
INTRODUCTION

Thyroid hormone by binding to the thyroid hormone receptors affects metabolism and growth in nearly all tissues of the body. Thyroid hormones play vital role in the synthesis and metabolism of lipids. The reduced secretion of thyroxine (T4) and triiodothyronine (T3) from the thyroid gland results in hypothyroidism. The subclinical hypothyroidism (SH) is term used for the condition in which there is small elevation of thyroid stimulating hormone (TSH) in the presence of normal thyroid hormone levels. Disorders of thyroid gland are the second most common endocrine abnormalities globally after diabetes mellitus.
\end{abstract}

\section{OBJECTIVE}

To determine the frequency of dyslipidemia in patients having subclinical hypothyroidism.

\section{METHODOLOGY}

This study was conducted at Naseer Teaching Hospital, Peshawar. Duration of the study was one years and the study design was descriptive cross sectional study. The total sample size was 136 patients presenting with subclinical hypothyroidism taking $34.31 \%$ proportion of dyslipidemia in subclinical hypothyroid patients ${ }^{12}$, 95\% confidence interval and $8 \%$ margin of error; using WHO software for sample size calculation. More over consecutive (non-probability sampling) technique was used for sample collection.

\section{RESULTS}

In this study mean age was 40 years with SD 1.26. Sixty three percent patients were female and $37 \%$ patients were male. Seventy percent patients had dyslipidemia while $30 \%$ patients didn't have dyslipidemia.

\section{CONCLUSION}

The current study shows that the incidence of dyslipidemia was found to be in patients having subclinical hypothyroidism.

\section{KEY WORDS}

dyslipidemia, subclinical, hypothyroidism.

\section{INTRODUCTION:}

Thyroid hormone by binding to the thyroid hormone receptors affects metabolism and

Correspondence:

Dr. Shah Zeb

Naseer Teaching Hospital

Contact: 0314-9396891

Email: sagheer_takkar@yahoo.com growth in nearly all tissues of the body. ${ }^{1}$ Thyroid hormones play vital role in the synthesis and metabolism of lipids. ${ }^{1}$ The reduced secretion of thyroxine (T4) and triiodothyronine (T3) from the thyroid gland results in hypothyroidism. ${ }^{2}$ The subclinical hypothyroidism $(\mathrm{SH})$ is term used for the condition in which there is small elevation of thyroid stimulating hormone (TSH) in the presence of normal thyroid hormone levels. ${ }^{2}$ Disorders of thyroid gland are the second most common endocrine abnormalities globally after diabetes mellitus. ${ }^{3}$ An international study results showed that the prevalence of subclinical hypothyroidism was $4.3 \%$ in general population, it also showed age and sex dependence. ${ }^{4}$ In another study it is reported that the prevalence of $\mathrm{SH}$ in general population is $4.3-9 \%$ and $16 \%$ in elderly females. ${ }^{4}$ In a national study, conducted among type 2 Diabetes Mellitus patients, $7.8 \%$ had $\mathrm{SH}^{5}$ 
The abnormalities in the lipid profile is a known complication of primary hypothyroidism, dyslipidemia in turn increases the risk of hypertension and cardiovascular diseases. ${ }^{6}$, The aim of this study is to determine the frequency of dyslipidemia in sub-clinical hypothyroidism patients in our setup. This hasn't been studied in our setup especially the dyslipidemia in patients having subclinical hypothyroidism. The knowledge of the frequency of dylipidemia in patients with subclinical hypothyroidism in our setup will enable us to detect and treat dyslipidemia early and reduce the overall cardiovascular risk in such patients.

\section{MATERIALS AND METHODS}

This study was conducted at Naseer Teaching Hospital, Peshawar. Duration of the study was one years and the study design was descriptive cross sectional study. The total sample size was 136 patients presenting with subclinical hypothyroidism taking $34.31 \%$ proportion of dyslipidemia in subclinical hypothyroid patients $12,95 \%$ confidence interval and $8 \%$ margin of error; using WHO software for sample size calculation. More over consecutive (non-probability sampling) technique was used for sample collection. All patients of subclinical hypothyroidism not taking thyroxin or anti lipids drugs, patients of either gender and patients of age $18-60$ years were included while hypothyroid patients on treatment. clinical hypothyroidism, ischemic heart diseases, renal disease, hepatic disease, Type 1 and type 2 diabetes mellitus, patients taking anti-lipids drugs, history of alcoholism, pregnancy were excluded from the study. The above mentioned conditions act as confounder and if included had introduce bias in the study result.

The study was conducted after approval from hospitals ethical and research committee. All patient meeting the inclusion criteria and presenting with subclinical hypothyroidism as per operational definition was included in the study. All patients were worked up with detailed history, clinical examination and investigations like Thyroid function tests (TFTs), Fasting lipid profile (FLP), fasting blood sugar (FBS), Renal function tests (RFT), Liver function tests (LFT) and also relevant investigations to rule out other contributing factors for dyslipidemia in these patients. All the investigations were sent to the main pathology laboratory of Naseer Teaching Hospital, Peshawar. FLP and FBS were performed after overnight fasting. The purpose and benefits of the study was explained to all patients and they were assured that the study is done purely for research and data publication and if agreed upon, a written informed consent had obtained for interview. Detailed interview and data collection was done. The exclusion criteria were strictly followed to control confounders and exclude bias in study result. All the result were followed by myself and all the above mentioned information including name, age, gender, findings on laboratory tests were recorded in a pre designed proforma. Data was analyzed by using Statistical Package for Social Sciences (SPSS) version 16.0. Mean \pm standard deviation was calculated for continuous variables like age of patients. Frequency and percentages were calculated for qualitative variables like gender, dyslipidemia. Dyslipidemia was stratified among age, gender and thyroid status to see effect modifiers. Results were presented as tables / charts.

\section{RESULTS}

This study 136 patients were observed in which 34(25\%) patients were in age ranged from 21-30 years, $38(28 \%)$ patients were in age ranged from 31-40 years, $41(30 \%)$ patients were in age ranged from 41-50 years, 23(17\%) patients were in age ranged from 51-60 years, Mean age was 40 years with SD 1.26. Eighty six $63 \%$ patients were female and $50(37 \%)$ patients were male. The incidence of dyslipidemia was found to be $70 \%$ in our setup. Stratification of dyslipidemia with age distribution was analyzed as in 95 cases dyslipidemia 24 patients were in age ranged from 21-30 years, 28 patients were in age ranged from 31-40 years, 27 patients were in age ranged from 4150 years, 16 patients were in age ranged from $51-60$ years. Chi square test in table 4 , the $P$ value was 0.8996 and Chi square test in table 5 , the $P$ value was 0.6773 . 
Table 1: Age Distribution $(n=136)$

\begin{tabular}{|l|l|l|}
\hline AGE in (YEARS) & FREQUENCY & PERCENTAGE (\%) \\
\hline $\mathbf{2 1 - 3 0}$ & 34 & $25 \%$ \\
\hline $\mathbf{3 1 - 4 0}$ & 38 & $28 \%$ \\
\hline $\mathbf{4 1 - 5 0}$ & 41 & $30 \%$ \\
\hline $\mathbf{5 1 - 6 0}$ & 23 & $17 \%$ \\
\hline Total & 136 & $100 \%$ \\
\hline
\end{tabular}

Table 2: Gender Distribution $(\mathrm{n}=136)$

\begin{tabular}{|l|l|l|}
\hline GENDER & FREQUENCY & PERCENT \\
\hline Female & 86 & $63 \%$ \\
\hline Male & 50 & $37 \%$ \\
\hline Total & 136 & $100 \%$ \\
\hline
\end{tabular}

Table 3: Frequency of Dyslipidemia in Subclinical Hypothyroidism $(n=136)$

\begin{tabular}{|l|l|l|}
\hline DYSLIPIDEMIA & FREQUENCY & PERCENT \\
\hline Yes & 95 & $70 \%$ \\
\hline No & 41 & $30 \%$ \\
\hline Total & 136 & $100 \%$ \\
\hline
\end{tabular}

Table 4: Stratification of Dyslipidemia with Age Distribution $(n=136)$

\begin{tabular}{|l|l|l|l|l|l|}
\hline DYSLIPIDEMIA & $\begin{array}{l}21-30 \\
\text { years }\end{array}$ & $\begin{array}{l}31-40 \\
\text { years }\end{array}$ & $\begin{array}{l}41-50 \\
\text { years }\end{array}$ & $\begin{array}{l}51-60 \\
\text { years }\end{array}$ & Total \\
\hline Yes & 24 & 28 & 27 & 16 & 95 \\
\hline No & 10 & 10 & 14 & 7 & 41 \\
\hline Total & 34 & 38 & 41 & 23 & 136 \\
\hline
\end{tabular}

Table 5: Stratification of Dyslipidemia with Gender Distribution $(n=136)$

\begin{tabular}{|l|l|l|l|}
\hline DYSLIPIDEMIA & Male & Female & Total \\
\hline Yes & 36 & 59 & 95 \\
\hline No & 14 & 27 & 41 \\
\hline Total & 50 & 86 & 136 \\
\hline
\end{tabular}

\section{DISCUSSION}

Subclinical hypothyroidism (SH) is more frequent in areas of iodine sufficiency as compared to iodine deficient areas. The burden of $\mathrm{SH}$ in $\mathrm{KPK}$ is expected to increase with increasing iodine sufficiency. Studies have shown conflicting results concerning not only the degree of lipid changes in $\mathrm{SH}$ but also the effect of thyroxine substitution therapy. The effects of thyroxine replacement on lipid levels are at not completely understood. Dyslipidemia is defined as the abnormal amount of lipids [total cholesterol (TC), low density lipoprotein cholesterol (LDL-C), 
high density lipoprotein cholesterol (HDL-C) and triglyceride (TG)] in the blood. ${ }^{8}$ The normal values are TC $(<200 \mathrm{mg} / \mathrm{dl})$, LDL-C $(<100 \mathrm{mg} / \mathrm{dl})$, HDL-C $(>60 \mathrm{mg} / \mathrm{dl})$ and TG $(<150 \mathrm{mg} / \mathrm{dl}){ }^{8}$ Hypothyroidism is a important cause of secondary dyslipidemia. ${ }^{9}$ In a local study, the prevalence of dyslipidemia among general population was $59.1 \% .{ }^{10}$ Our study shows that. The mean age of the patients was 40 years with SD 1.26. Sixty three percent patients were female and $37 \%$ patients were male. Similar results were found in other studies as the mean age of patients in subclinical hypothyroid groups are $38.76 \pm 11.82$ years, suggesting that mean age of patients of hypothyroidism seeking healthcare is around 40 years. These persons are more prone to cardiovascular complications and other problems. If treatment and other lifestyle interventions are initiated at a proper time these complications can be delayed, if not fully corrected. In the present study majority of the subjects i.e. $57 \%, 60 \%, 70 \%$ respectively in subclinical hypothyroid were females. These findings suggest that hypothyroidism is much more prevalent in the female population.

Our study shows that the frequency of dyslipidemia in patients having subclinical hypothyroidism was $70 \%$. Similar results were found in study done by LU L et al ${ }^{15}$ in which the frequency of dyslipidemia in patients having subclinical hypothyroidism was $63 \%$. Al Sayed A et al ${ }^{16}$ had also observed the frequency of dyslipidemia in patients having subclinical hypothyroidism was $67 \%$. A study conducted in Nepal found an association between hypothyroidism and dyslipidemia, hypercholesterolemia was found in $48.4 \%$, hypertriglyceridemia was seen in $32.3 \%$ of hypothyroid patients. ${ }^{3}$ In a study conducted in Japan it was noted that, among hypothyroid patients, females of age more than 55 years $40.3 \%$ had high levels of low density lipoprotein cholesterol (LPL-C), which was much higher than the females of age less than 55 years (17.8\%) and male patients $(26.5 \%) .{ }^{11}$ Results of the study showed that levels of triglycerides were high in $\mathrm{SH} .{ }^{2}$ Result of a study conducted in China showed that the prevalence of dyslipidemia among SH patients was higher (34.31\%)than euthyroid patients $(31.18 \%)^{12}$. Result of a study conducted in India showed that the prevalence of dyslipidemia in clinical hypothyroidism is $65.06 \% .{ }^{13}$ The cholesterol synthesis in stimulated by thyroid hormone by induction of 3-hydroxy-3-methyl-glutaryl coenzyme A reductase in the liver. ${ }^{6}$ Lipoprotein lipase activity is also affected by thyroid hormone and thus affecting the hydrolysis of triglycerides into very-low, density lipoprotein (VLDL) and chylomicrons into fatty acids and glycerol. ${ }^{6,14}$ In hypothyroid patients, lipoprotein lipase activity in the adipose tissue is normal or decreased, in addition to decreased hepatic lipase activity resulting in normal or high levels of triglycerides. ${ }^{6}$

\section{CONCLUSION}

The study has demonstrated and has further proved that hypothyroidism also causes dyslipidemia. Thus, it may be a good practice to screen patients with hypothyroidism for evidence of metabolic syndrome and in preventing various other complications. The screening and treatment for subclinical hypothyroidism should be done to prevent its adverse effects on lipid metabolism. Thyroid hormones regulate the expression of enzymes involved in all steps of lipid metabolism leading to the development of qualitative and quantitative changes of lipids, in thyroid disease. Dyslipidemia coexists with other metabolic abnormalities, including, hypertension, insulin resistance, and oxidative stress, all of them being risk factors for other diseases. In addition, dyslipidemia induces insulin resistance and oxidative stress, via a vicious cycle. However, more studies need to be done, especially prospective, to elucidate the real significance of dyslipidemia or other metabolic changes in clinical and, even more, in subclinical hypothyroidism. 


\section{REFERENCES}

1) Marwaha RK, Tandon N, Garg MK, Kanwar R, Sastry A, Narang A, et al. Dyslipidemia in subclinical hypothyroidism in an Indian population. Clinical Biochemistry. 2011;44:1214-7.

2) Saini V, Yadav A, Arora S, Singh $R$ and Bhattacharjee J. Association between different degrees of hypothyroidism and serum lipids. Internet Journal of Medical Update. 2012;7(2):3-8.

3) Regmi $A$, Shah $B$, Rai BR,Pandeya A. Serum lipid profile in patients with thyroid disorders in central Nepal. Nepal Med Coll J 2010;12(4):253-6.

4) Arishma T, Ito M, Sasaki I, Hiraiwa T, Kubota S, Fukata S, et al. Effect of levothyroxine replacement on postprandial hyperlipidemia in patients with subclinical hypothyroidism. Bulletin of the Osaka Medical College. 2010;56(2):41-8.

5) ShahbazianHB ,Behbahani AM, Mohtashami AZ. Prevalence of thyroid dysfunction and thyroid auto antibodies in type 2 diabetic patients. Pak J Med Sci. 2011;27(5):1169-72.

6) Peppa M, Grigoria B, Dimitriades G. Lipid abnormalities and cardiometabolic risk in patients with overt and subclinical thyroid disease. Biomarker Insights. 2011 Article ID 575840.

7) Biondi B, Cooper DS. The clinical significance of subclinical thyroid dysfunction. Endocr Rev. 2008;29:76131.

8) Jellinger PS, Smith DA, Mehta AE, Ganda O, Handelsman Y, Rodbard HW, et al.American association of clinical endocrinologists' guidelines for management of dyslipidemia and prevention of atherosclerosis. EndocrPrac.2012;18:1-78.

9) Rizos CV, Elisaf MS, Liberopoulos EN. Effects of thyroid dysfunction on lipid profile. The Open Cardiovasc Med J.2011;5:76-84.

10) Basharat Z, Mumtaz S, Rashid F, Rashid S, Mallam SA, Diljan A, et al. Prevalence of risk factors of ischemic stroke in a local Pakistani population. High-density lipoproteins, an emerging risk factor. Neurosciences.2012;17:357-62.

11) Zhu $X$, Cheng SY. New insights into regulation of lipid metabolism by thyroid hormone. CurrOpinEndocrinol Diabetes Obes.2010;17(5):408-13.

12) Lai $Y$, Wang J, Jiang $F$, Wang $B$, Chen $Y$, Li M, et al. The relationship between serum thyrotropin and components of metabolic syndrome. Endocr J.2011;58:23-30.

13) Saxena A, Kapoor P, Saxena S, Kapoor AK. Effect of levothyroxine therapy on dyslipidemia in hypothyroid patients. Internet Journal of Medical Update.2013;8(2):39-49.

14) KhanA, Khan MMA, Akhtar S. Thyroid Disorders, Etiology and Prevalence. J Med Sci 2002;2:89-94.

15) MacCarthy $P A$,Shah AM.Impaired endothelium-dependent regulation of ventricular relaxation in pressure-overload in cardiac hypertrophy. Circulation 2000;101:1854-61.

16) Al Sayed A, Al Ali N, Bo Abbas Y, Alfadhli E. Subclinical hypothyroidism is associated with early insulin resistance in Kuwaiti women. Endocrine Journal 2006;53:653-7.

LICENSE: JGMDS publishes its articles under a Creative Commons Attribution Non-Commercial Share-Alike license (CC-BY-NC-SA 4.0) COPYRIGHTS: Authors retain the rights without any restrictions to freely download, print, share and disseminate the article for any lawful purpose. It includes scholarly networks such as Research Gate, Google Scholar, LinkedIn, Academia.edu, Twitter, and other academic or professional networking sites. 